\title{
PADRÕES ESPAÇOS-TEMPORAIS DA ROTA DO COVID19 (CORONAVIRUS) NO ESTADO DE SANTA CATARINA, BRASIL
}

\section{SPACE-TEMPORAL PATTERNS OF THE COVID19 ROUTE (CORONAVIRUS) IN THE SANTA CATARINA STATE, BRAZIL}

\author{
Eduardo Augusto Werneck Ribeiro \\ Instituto Federal Catarinense \\ eduardo.ribeiro@ifc.edu.br
}

\begin{abstract}
RESUMO
Este artigo trata-se de uma análise dos padrões espaços temporais do COVID19 em Santa Catarina, Brasil em dois momentos:entre março e abril de 2020. A metodologia aplicada considerou a configuração e tipificação espacial de seus municípios a partir de dois estudos do IBGE e os casos confirmados dos municípios em Santa Catarina. Não se avaliou o número de casos, nem de óbitos. A partir dos resultados, identificou-se três dinâmicas espaciais distintas (grau de urbanização e concentração populacional), com dois fluxos difusores da COVID19. Com crescimento do número de municípios com casos confirmados e com características distintas entre eles, o cenário futuro implicará planejamento e adequação da infraestrutura de atendimento emergencial diferenciado no enfrentamento da COVID19 no estado de Santa Catarina, Brasil.
\end{abstract}

Palavras chaves: espaço-tempo. aglomerações populacionais. tipificação dos municípios. fluxos.

\begin{abstract}
This article is an analysis of the time-space patterns of COVID19 in Santa Catarina, Brazil in two moments between March and April 2020. The applied methodology took into consideration the spatial configuration and typification of its municipalities from two studies by IBGE superimposing the confirmed cases of the municipalities in Santa Catarina. The number of cases and deaths was not evaluated. The results point to three distinct spatial dynamics (degree of urbanization and population concentration), with two diffusing flows from COVID19. With growing number of municipalities with confirmed cases and with different characteristics among them, the future scenario will involve planning and adequacy of the emergency response infrastructure differentiated in fighting COVID19 in the state of Santa Catarina, Brazil.
\end{abstract}

Keywords: space-time. population agglomerations. typification of municipalities. flows.

\section{INTRODUÇÃO}

A disseminação do COVID19 (Coronavirus) no Brasil apresentou um quadro epidemiológico complexo e mostrou o tamanho e os diferentes arranjos geográficos da saúde do país. Em cada ente federativo, pode-se observar diferentes estratégias de enfrentamento, tanto das autoridades sanitárias (em conter) quanto o vírus (em propagar) no uso dos circuitos espaciais (fluxos e fixos) para seu sucesso. Este quadro ainda mostrou problemas com relação aos casos confirmados e óbitos. Mesmo que existam dúvidas sobre a subnotificação, somando as polêmicas por conta da medida de distanciamento social, são necessárias evidências e formas sistemáticas para interpretálas, conforme aponta Spiess (2020).

Recebido em: 27/04/2020

Aceito para publicação em: 26/05/2020. 
Neste sentido, este artigo problematizará a questão da espacialização temporal dos casos confirmados da COVID19 no estado de Santa Catarina a partir de dois períodos. O primeiro, do primeiro caso confirmado a 6 de abril de 2020. O segundo é a atualização deste estudo até o dia 17 do mesmo mês. O raciocínio geográfico é uma estratégia que pode agregar no entendimento de quais de variáveis territoriais propiciam a propagação do vírus, portanto, um reforço aos modelos epidemiológicos já em uso.

Em Ribeiro (2020) evidenciou-se que a difusão espacial do vírus se apropria de uma estrutura espacial diferenciada a partir de duas variáveis: densidade populacional e mobilidade. Para Mattedi (2020) se a probabilidade de transmissão local é sustentada em unidades populacionais mais densas, mais estendidas temporalmente devem ser as medidas de distanciamento social. Isso deve ser feito, porque a concentração espacial da população aumenta a intensidade das trocas entre os indivíduos. Temos a premissa de que a dinâmica espacial do vírus ocorre por meio das seguintes dualidades: densidade/concentração populacional e mobilidade/fluxo.

Com base nessa premissa, cabe discutir as seguintes dimensões do raciocínio geográfico: qual é perfil dos municípios acometidos? Quais são as características demográficas desses municípios? Em que medida o circuito espacial (fluxos e os fixos) permite compreender a dinâmica de propagação do vírus? Não trataremos de análise da incidência, taxa de mortalidade, teremos apenas como referência a presença de casos confirmados por município.

Tendo em vista a nova instrução do decreto 554 de 11 de abril de 2020 que altera as medidas para enfrentamento da emergência de saúde pública decorrente do COVID19 em Santa Catarina ${ }^{2}$, não podemos descartar os impactos que tal medida implicará nos fluxos das cidades que serão expostas aos novos casos de COVID19.

Diante disto, avaliaremos a densidade e mobilidade a partir do papel dos municípios com casos de covid19 confirmados na rede hierárquica de serviços (aglomeradas ou isoladas) e suas características quanto a sua população (urbana ou rural). Ressalta-se que em Ribeiro (2020), foi identificado no estado de Santa Catarina, três regiões com distintas dinâmicas para a propagação do vírus: a região litorânea, região centro-serrana e oeste catarinense. Buscaremos a partir deste recorte, avaliar a dinâmica da dispersão dos casos de COVID19.

\section{METODOLOGIA}

Utilizou-se em um primeiro momento, dados georreferenciados, disponibilizados pelo Instituto Brasileiro de Geografia e Estatística (IBGE), a partir das seguintes publicações:

1) Classificação e caracterização dos espaços rurais e urbanos do Brasil: uma primeira aproximação (2017);

2) Arranjos populacionais e concentrações urbanas no Brasil (2016);

Em um segundo momento, agregou-se a informação dos municípios com casos confirmados de COVID19, fornecidos pela Secretaria do Estado de Saúde de Santa Catarina. Tais dados são atualizados diariamente nos boletins emitidos por este órgão.

Todas estas informações foram reunidas em uma tabela, indexadas com os códigos de identificação dos municípios fornecidas pelo IBGE. Cada variável foi acrescida como coluna. A tabela foi geocodificada em um arquivo tipo shapefile dos municípios de Santa Catarina, fornecido pelo mesmo instituto. Foi utilizado o software QGIS para o geoprocessamento e interpolação das informações.

Para os mapas categorizados, as classes foram ajustadas a partir do algoritmo que emprega o método natural jenk. Esse método identifica as quebras entre as classes, minimizando a soma da variância dentro de cada classe.

Para o mapa final da dinâmica temporal, foi interpolado centroides da localização das sedes dos municípios, usando como dado, as datas do primeiro caso confirmado por município. O algoritmo empregado foi o da Ponderação pelo Inverso da Distância (IDW), onde o resultado foi uma camada raster em tons de cinza. Aplicou-se uma paleta de cores, ajustada pelos valores exportados da

${ }^{2}$ Ver a integra do decreto em: http://www.doe.sea.sc.gov.br/Portal/ListarJornal.aspx

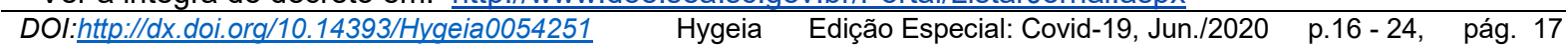


interpolação. Assim, os dados mais antigos estão representados na cor vermelha e os mais recentes na cor azul.

Os dois primeiros mapas apresentados (Figuras 1 e 2) a seguir, se referem aos dados obtidos das publicações do IBGE: Classificação e caracterização dos espaços rurais e urbanos do Brasil: uma primeira aproximação (2017) e Arranjos populacionais e concentrações urbanas no Brasil (2016).

Figura 1 - Classificação das unidades populacionais segundo o grau de urbanização

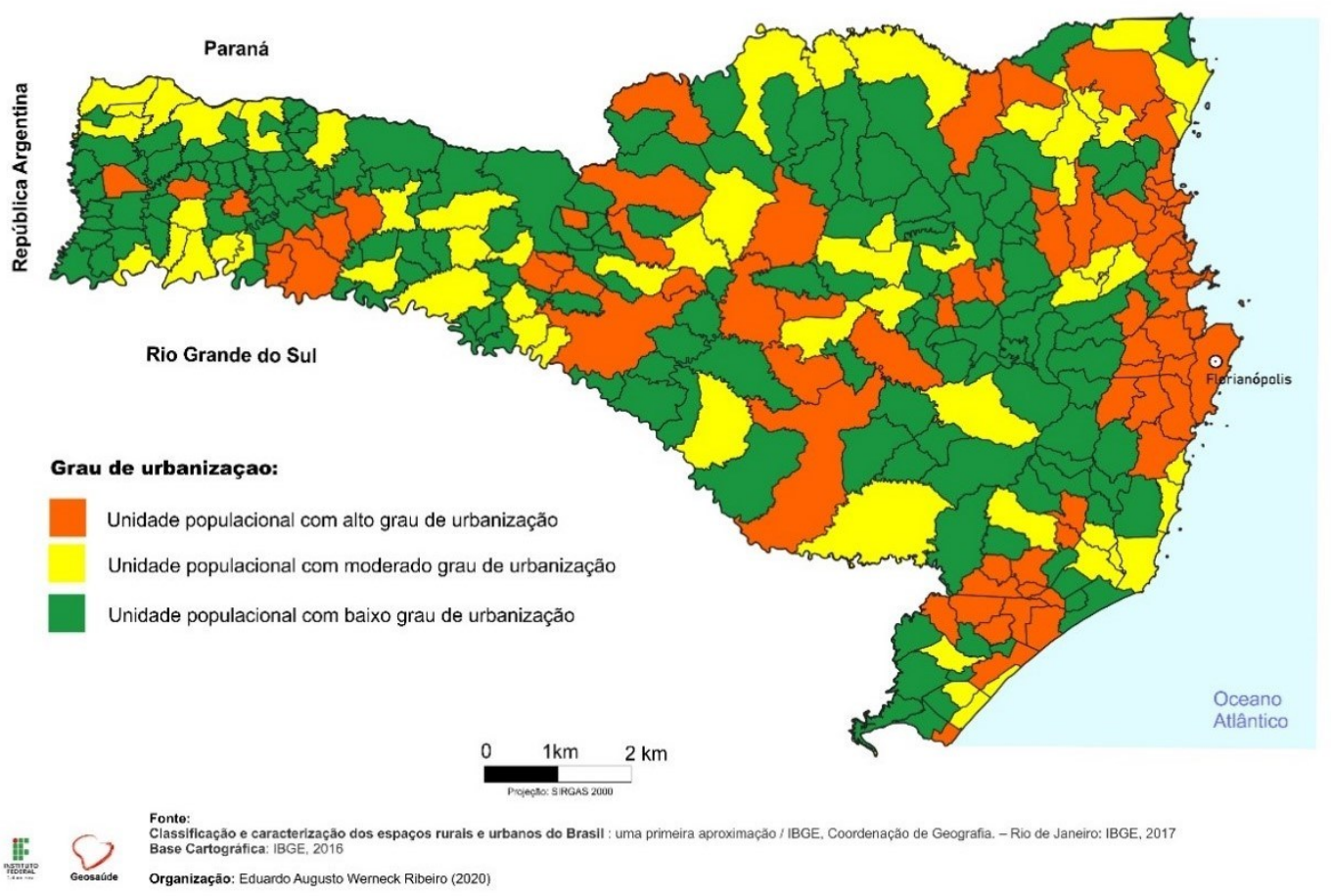

No estado de Santa Catarina, foi identificado, dos 295 municípios, 164 foram tipificados, segundo a metodologia aplicada pelo o IBGE (2017), como municípios predominantemente rurais, a partir dos seguintes parâmetros:

- municípios em Unidades Populacionais que possuem entre 25000 e 50000 habitantes em área de ocupação densa com grau de urbanização inferior a $25 \%$;

- municípios em Unidades Populacionais que possuem entre 10000 e 25000 habitantes

em área de ocupação densa com grau de urbanização inferior a $50 \%$; e

- municípios em Unidades Populacionais que possuem entre 3000 e 10000 habitantes em área de ocupação densa com grau de urbanização inferior a $75 \%$.

A figura 2 corresponde as informações aos Arranjos populacionais e concentrações urbanas no Brasil (2016).

Segundo o IBGE (2016), os tipos de arranjos populacionais são: Arranjos Populacionais Fronteiriços, Arranjos Populacionais Turísticos e de Veraneio no Litoral, Arranjos Populacionais até 100000 habitantes, Médias Concentrações Urbanas e Grandes Concentrações Urbanas. No caso deste estudo, consideramos os arranjos populacionais. 


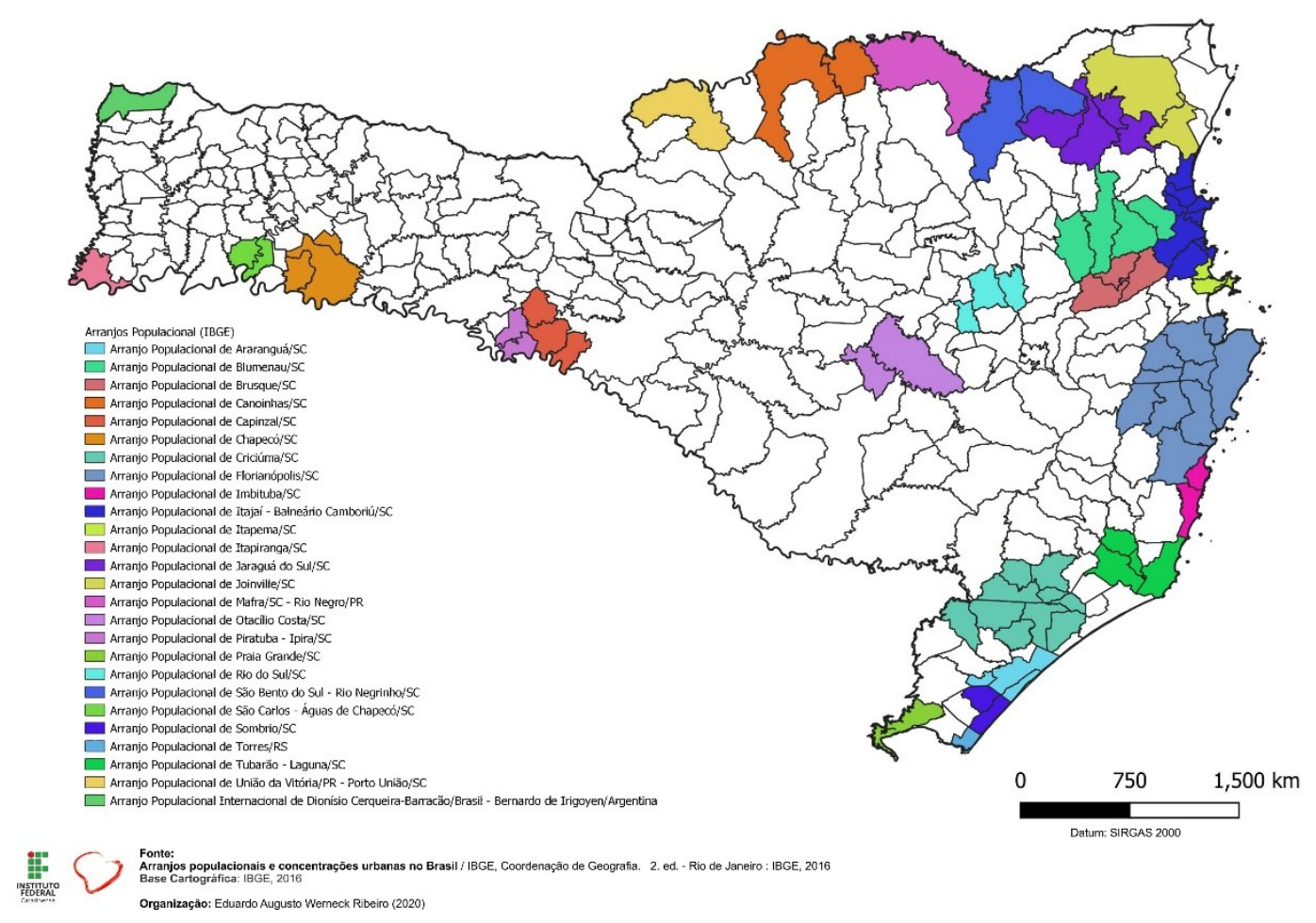

A figura 2, apresenta o caso catarinense, onde encontramos 26 arranjos: 1 Arranjo Internacional, 6 Arranjos Populacionais Turísticos e de Veraneio no Litoral, 8 Arranjos Populacional com até 100 mil habitantes, 10 Arranjos de Médias Concentrações Urbanas e 1 Grandes Concentrações Urbanas.

\section{RESULTADOS E DISCUSSÃO}

A partir das perguntas norteadoras, podemos comparar as duas informações descritas em Ribeiro (2020) e com as atuais, dinâmica ocorrida entre 6 a 17 de abril de 2020. Ressalta-se que dividimos geograficamente, o estado em 3 regiões: Litoral, centro-serrana e oeste para esta discussão. Passaremos a analisar as informações a partir das figuras 3, 4 e 5, respectivamente. Sobre quais o qual é perfil dos municípios acometidos, vejamos a figura 3

Em 6 de abril de 2020, já constava a contaminação comunitária (CAROLINA HOLLAND, 2020) em Santa Catarina. Na figura 3-A, é possível observar o grau de urbanização e os municípios com casos confirmados. Naquela época, constatou-se que $91 \%$ dos municípios enquadrados como urbanos e $60 \%$ dos municípios enquadrados como moderado grau de urbanização, tinham casos confirmados. O conjunto majoritário dos municípios estavam na região do litoral. Para os dados do dia 17 de abril, figura 3-B, este conjunto de municípios no litoral tem um aumento, onde verifica-se que $99 \%$ dos municípios tipificados como urbanos e $95 \%$ dos moderados, assim, representando quase a totalidade do perfil moderado e urbano na região litorânea. Para a região centro-serrana, a pouca presença do COVID19 é representada com 9 municípios em 6 de abril (Figura $3-A$ ), dentre eles, 2 com o perfil urbano. Este número não representa $10 \%$ dos municípios desta região estabelecida. No entanto, com os dados de 17 de abril (Figura 3-B), este número subiu para 16 municípios, sendo 9 municípios com grau de urbanização rural. A região oeste, por sua vez, em 6 de abril contava com 4 municípios, um com grau urbano, 2 moderados e 1 rural (Figura 3-A). Já no período seguinte, o número passou para 10 , sendo 6 rurais. 
Figura 3 - Casos de Covid 19 de acordo com o grau de urbanização: (A) 6 de abril e (B) 17 de abril

(A)
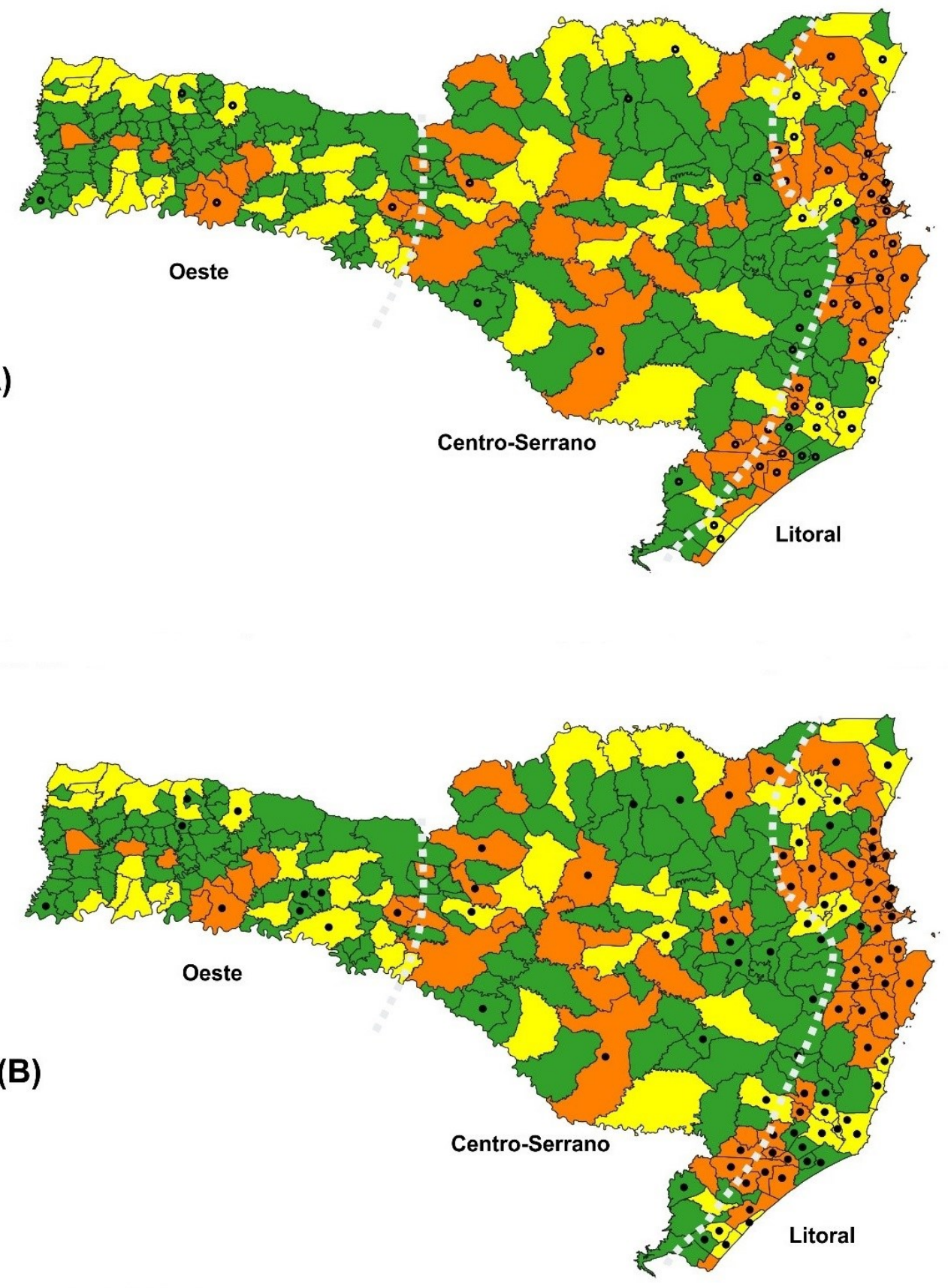

Casos confirmados

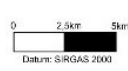

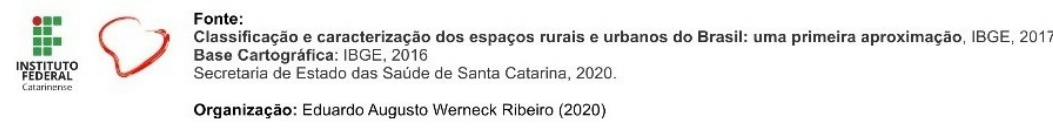


Esta variável mostra que os municípios acometidos das três regiões estabelecidas, são de perfis diferentes. Este é um aspecto que se deve observar na difusão espacial do COVID19 em Santa Catarina. A presença da grande quantidade de casos na região predominantemente urbana (litoral), a pouca no centro-serrana com uma população moderada-rural e os crescentes casos no oeste, predominantemente rural, implica observar que a população contaminada ainda é residente na cidade em número absolutos, no entanto, ao olharmos para as particularidades dos municípios, chama-se atenção para o grau rural nas regiões serranas e oeste.

Quanto as quais condições de aglomerações populacionais, vejamos a Figura 4.

Figura 4 - Casos confirmados COVID19 e os Arranjos Populacionais: (A) 6 de abril e (B) 17 de abril
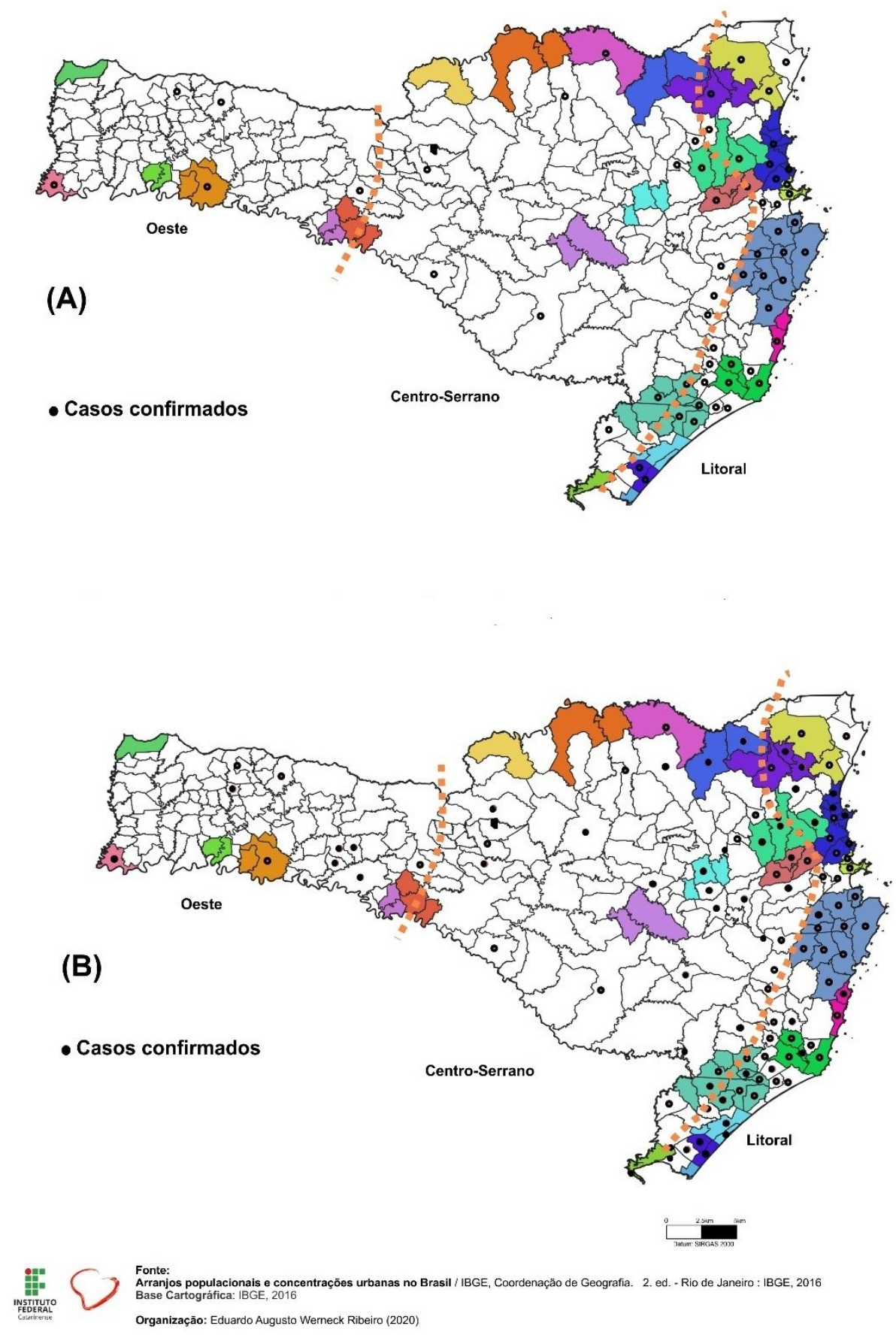
O estudo sobre os Arranjos populacionais do IBGE (2016) traz uma dimensão da mobilidade e proximidade na análise da difusão do COVID em Santa Catarina. Apesar das cidades serem tipificadas quanto ao grau urbano, não significa que a população é próxima e pendular. Ainda, a noção de cidade adota é além da concentração populacional, mas também a existência de um ambiente de trocas, de ligações, de transferências materiais e imateriais; portanto, um ambiente que envolve fluxos, circulação e escalas variadas. Ao sobrepormos ambas datas (4-A e 4-B), o resultado destaca o papel preponderante da infraestrutura urbana e o grau de mobilidade por ela gerada para a difusão do COVID19 no estado de Santa Catarina. Na região litorânea, os primeiros casos confirmados eram polos ou cidades que pertenciam aos arranjos. Este comportamento espacial se mostrou também para as demais regiões, porém em um ritmo menor.

As aglomerações por sua vez, são compostas por cidades polos, referências principais para transportes e destinos dos moradores que formam a aglomeração urbana para se obter produtos e serviços (compras, educação superior, aeroportos, serviços de saúde, aquisição de insumos e destino dos produtos agropecuários). Nota-se que todas as aglomerações no litoral apresentam casos confirmados. Desse modo, os fluxos entre os centros e cidades conectadas aos arranjos indicam que os circuitos e a facilidade de mobilidade são indicativos para os motivos para a rápida contaminação de cidades no litoral. O fato das regiões Centro-serrana e Oeste catarinense não terem grande quantidade de casos, explica-se pela baixa presença de aglomerados populacionais, onde a maioria das cidades apresentam um certo isolamento, ou seja, há pouca circulação mesmo em cidades tipificadas como urbanas e rurais. Ressalta-se que, apesar de ainda apresentarem poucos casos confirmados, essas duas regiões interioranas apresentam uma rede significativa de rodovias que se conectam aos estados vizinhos do Paraná e do Rio Grande do Sul, além da República Argentina. Portanto, há de se concluir que a pouca fluidez entre esses municípios, pode ser entendida como um dos principais fatores que dificultaram a propagação do COVID19 nessas regiões até 17 de abril (figura 4-B), e que o fomento à contaminação possa ocorrer via estados vizinhos e Argentina.

Dessa forma, os casos registrados em aglomerações fronteiriças, como no caso do município de Mafra, na divisa com o Paraná, e de Itapiranga, com Rio Grande do Sul, devem ser entendidos como interestaduais. Isso porque, mesmo que haja um controle por parte do poder público catarinense diante de com um possível aumento de casos, essa ação implicará em análises conjuntas com os estados fronteiriços, uma vez que o enfrentamento não dependerá apenas das autoridades de Santa Catarina.

Nota-se que esta possibilidade da circulação do vírus, além das fronteiras catarinense, é plausível. Observamos na região Oeste em 6 de abril, duas aglomerações importantes, não fronteiriços com a borda gaúcha, mas segundo o estudo do IBGE (2016) com forte fluidez com o Rio Grande do Sul. Em uma delas, Chapecó, mesmo com casos mais antigos, não houve aumento em 17 de abril. No entorno da segunda região, Concórdia, os 4 municípios próximos a fronteira gaúcha apresentaram casos confirmados, reforçando a hipótese da difusão vinda de outro estado (figura 4-B). Isto deve ser avaliado nos comparativos futuros, reforçando a análise de Ribeiro (2000), apontando que a dinâmica na região terá características próprias em relação as demais regiões do estudo.

Na busca por entender a difusão espaço temporal, propusemos um modelo de tendência espaço temporal, a partir da interpolação dos dados confirmados para o $1^{\circ}$ caso de cada município, a partir da metodologia explicada na seção anterior. Os resultados estão representados na Figura 5. 
Figura 5 - Evolução espaço temporal do COVID19 em Santa Catarina

(A)

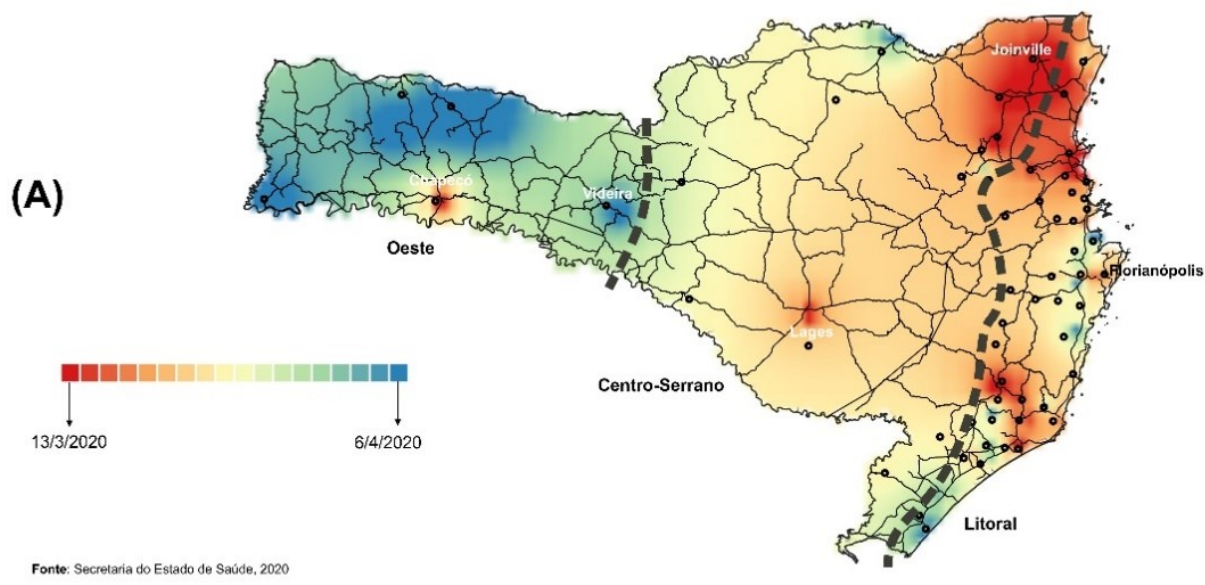

$6 / 4 / 200$

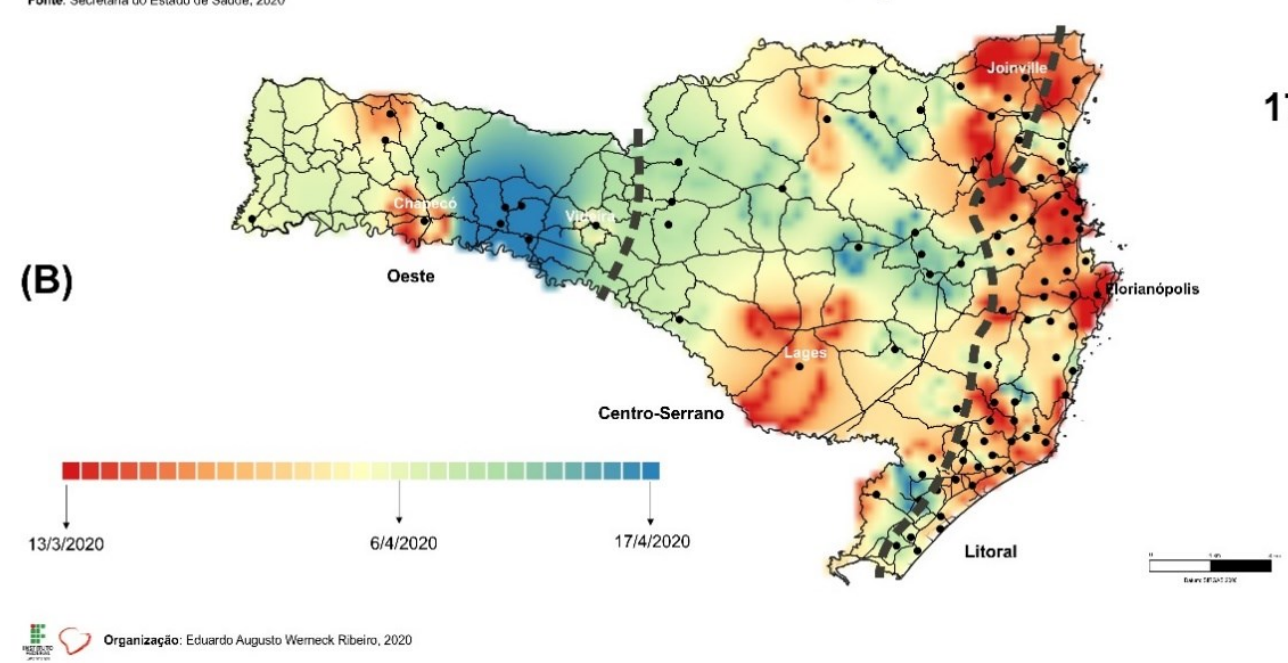

Os mapas gerados estão coloridos no vermelho para as datas mais antigas e a azul a mais recente. Para a data de 6 de abril (figura 5-A), evidenciou-se a concentração dos casos na região litorânea e pontos no centro-serrana e oeste. No entanto, para os dados de 17 de abril (figura 5 -B), nota-se uma mudança do fluxo espacial. Registra-se novos casos no litoral, vizinhos a locais com casos antigos, avançando para o centro do estado, ainda ocorrendo em municípios isolados, mas em direção ao aglomerado, corroborando com os argumentos sobre o grau de urbanização e arranjos populacional, conforme apontou Ribeiro (2020).

\section{CONSIDERAÇÕES FINAIS}

Houve uma mudança significativa dos municípios com casos registrados entre 6 de abril para 17 de abril. Tendo em vista o decreto estadual 554 do dia 11 de abril de 2020, coincide-se com sua publicação, as datas dos novos casos registrados neste estudo. Todavia, pondera-se a questão das notificações conforme discussão de Spiess (2000).

Os três circuitos espaciais da difusão do COVID19 em Santa Catarina apontados em Ribeiro (2000) apresentaram novos fluxos de difusão com os dados de 17 de abril. Foi possível identificar duas direções: a) Sentido litoral para o centro-serrana e b) No Oeste, vindo das bordas fronteiriças do Paraná e Rio Grande do Sul, sendo a borda gaúcha a mais ativa nos novos casos registrados. Registra-se a não presença de casos, até o momento, com a fronteira da República Argentina. A dinâmica dos casos indica a necessidade de extrapolar a escala do estado de Santa Catarina para se entender o fluxo e suas implicações futuras. 
Reforça-se o papel da configuração e arranjos espaciais das regiões no entendimento da propagação do vírus. A região centro-serrana e oeste não tem a mesma quantidade de aglomerações populacionais que a litorânea, entretanto, o perfil predominante de municípios enquadrados como grau moderados e rurais, respectivamente, implica pensar que esta característica é imprescindível para entender a progressão do vírus na região (distância e acessibilidade aos serviços de atendimento, por exemplo).

Apesar de contar com poucas aglomerações populacionais, os municípios isolados não estão seguros de futuras contaminações, uma vez que são dependentes das cidades polos para prestação de serviços de média e alta complexidade no setor de saúde, entre outros, como mencionados na seção anterior e dos eixos rodoviários que conectam outros municípios que já contam com casos confirmados. Esta situação reforça o papel da hierarquia urbana na região centro-serrana e oeste na difusão e na dificuldade em adequar a infraestrutura de atendimento emergencial, principalmente no que se refere a custos e ofertas de novos leitos para internação.

Ressalta-se que diferente da região litorânea, as duas regiões em tela, contemplam taxas de pobreza (centro-serrana) e assentamentos rurais (oeste), conforme apontam Silva (2018) e NSC TV (2017).

Assim, este perfil de vulnerabilidade acentuado, indica a necessidade de aprofundar a análise para identificar as especificações de cada região e seus municípios, tendo e vista, a identificação de processos espaço-temporais na escala intraurbana para subsidiar as diferentes ações necessárias para o enfrentamento do COVID19.

\section{REFERÊNCIAS BIBLIOGRÁFICAS}

CAROLINA HOLLAND (G1 Santa Catarina). Governo de SC decreta situação de emergência por causa do coronavírus: Estado confirmou transmissão comunitária de Covid-19. Mais de 200 casos suspeitos ainda são monitorados. 2020. Disponível em: https://g1.globo.com/sc/santacatarina/noticia/2020/03/17/governo-de-sc-decreta-situacao-de-emergencia-por-causa-docoronavirus.ghtml. Acesso em: 17 mar. 2020.

IBGE. Arranjos populacionais e concentrações urbanas no Brasil / IBGE, Coordenação de Geografia. - 2. ed. - Rio de Janeiro : IBGE, 2016 Disponível em: https://biblioteca.ibge.gov.br/visualizacao/livros/liv99700.pdf . Acesso em: 18 abr. 2020.

IBGE. Classificação e caracterização dos espaços rurais e urbanos do Brasil : uma primeira aproximação / IBGE, Coordenação de Geografia. Rio de Janeiro: IBGE, 2017 Disponível em: https://biblioteca.ibge.gov.br/visualizacao/livros/liv100643.pdf . Acesso em: 18 de abr. 2020.

NSC TV (Santa Catarina). Na Serra de SC, 13 mil famílias vivem na pobreza e extrema pobreza, diz pesquisa: Associação dos Municípios da Região Serrana fez estudo. Secretaria diz que acompanha famílias.2017. Disponível em https://g1.globo.com/sc/santa-catarina/noticia/na-serra-de-sc-13-milfamilias-vivem-na-pobreza-e-extrema-pobreza-diz-pesquisa.ghtml

MATTEDI, Marcos. Efeitos espaciais no distanciamento social. 2020. Disponível em: https://www.netdr.org/post/efeitos-espaciais-no-distanciamento-social-17-04. Acesso em: 17 abr. 2020.

RIBEIRO, Eduardo Augusto Werneck. A dinâmica de transmissão COVID19 em Santa Catarina. 2020. Disponível em: https://www.net-dr.org/post/a-din\%C3\%A2mica-de-transmiss\%C3\%A3ocovid19-em-santa-catarina. Acesso em: 11 abr. 2020.

SILVA, Jefferson Chaves da. POBREZA MULTIDIMENSIONAL NAS MESORREGIÕES CATARINENSES: um estudo a partir da abordagem das necessidades básicas. 2018. 85 f. TCC (Graduação) - Curso de Ciências Econômicas, Economia e Relações Internacionais, Universidade Federal Catarinense, $\quad$ Florianópolis, 2018. $\quad$ Disponível em: https://repositorio.ufsc.br/bitstream/handle/123456789/188568/Monografia\%20Jefferson\%20Chaves.p df?sequence=1. Acesso em: 11 abr. 2020.

SPIESS, Maiko Rafael. O Fantasma da subnotificação. 2020. Disponível em: https://www.netdr.org/post/o-fantasma-da-subnotifica\%C3\%A7\%C3\%A3o-16-04. Acesso em: 16 abr. 2020. 